\title{
Surgical Site Infections Following Cesarean Section: A Longitudinal Study
}

\author{
Esha R Shanbhag ${ }^{1}$, Veena $P^{2}$ (D)
}

\begin{abstract}
Aim and objective: To find the incidence of surgical site infections following cesarean section and to assess the associated risk factors and the common pathogens involved in these wound infections.

Materials and methods: The study was conducted from November 2014 to June 2016. A total of 548 women were included. Data were collected from patients and medical records in a semi-structured proforma and wound site examined till discharge of the patients. After discharge, patients were followed by telephone on day 14 and 30.

Results: The mean age of the women was $26.20 \pm 4.385$ years. The mean BMI was $25.965 \pm 4.18 \mathrm{~kg} / \mathrm{m}^{2}$. Forty women out of the total 548 developed surgical site infections with an incidence rate of SSI of 7.3\%. Only three cases in them were deep SSI. Gram-negative organisms were the most isolated organisms in the infected cases with Escherichia coli being the most common organism. The key risk factors for infections found significant by multiple logistic regression analysis were obesity, severe anemia, prolonged rupture of membranes, multiple vaginal examinations, emergency basis, extended duration of surgery, and skin closure by mattress sutures with silk sutures.

Conclusion: The infection rate is significantly associated with severe anemia and obesity, prolonged rupture of membranes, multiple vaginal examinations, emergency procedures, prolonged duration of surgery, and silk as a suture material for skin closure with mattress suture.

Keywords: Cesarean section, Premature rupture of membranes, Severe anemia, Surgical site infection.

Journal of South Asian Federation of Obstetrics and Gynaecology (2021): 10.5005/jp-journals-10006-1889
\end{abstract}

\section{INTRODUCTION}

Cesarean section is a commonly performed surgical procedure in obstetric practice. Recent trends have shown a dramatic increase in the incidence of the operation with simultaneous increase in the maternal morbidity caused by it. Urinary tract infections and postoperative infections are the two leading causes of infection. ${ }^{1}$ Wound infections have an adverse impact on the patients in terms of socioeconomic consequences and increased healthcare costs. ${ }^{2}$

Surgical site infections act as a surrogate marker of nosocomial infections and a key quality indicator of patient care. Reported rates of the wound infection vary due to the differences in the criteria to diagnose infections, regional variations in risk factors, and varying lengths of postoperative follow-up. ${ }^{3}$ MoirBussy conducted hospital survey and reported it to be $0-25 \% .{ }^{4}$ Surveillance is a vital step in preventing wound infections as it provides an insight into the magnitude of the problem and helps to take preventive measures and curtail the infections. ${ }^{5,6}$ We plan to study the incidence of surgical site infections, assess the risk factors, and identify the most common pathogens involved in the same in our hospital setup.

\section{Materials and Methods}

The study was carried out prospectively in the Department of Obstetrics and Gynaecology, JIPMER, Pondicherry, from November 2014 to June 2016. The study protocol was approved by Institutional Ethics Committee.

As seen by our hospital statistics of nearly 2,500 cesarean deliveries per year, sample size was estimated to be 548 to detect $5 \%$ prevalence of surgical site infections. In the postoperative
${ }^{1}$ Department of Gyneoncology, Kidwai Memorial Institute of Oncology, Bengaluru, Karnataka, India

${ }^{2}$ Department of Obstetrics and Gynaecology, Jawaharlal Nehru Institute of Post Graduate Medical Education and Research, Puducherry, India

Corresponding Author: Esha R Shanbhag, Department of Gyneoncology, Kidwai Memorial Institute of Oncology, Bengaluru, Karnataka, India, Phone: +91 09943629370, e-mail: eshars@gmail.com

How to cite this article: Shanbhag ER, Veena P. Surgical Site Infections Following Cesarean Section: A Longitudinal Study. J South Asian Feder Obst Gynae 2021;13(3):77-80.

Source of support: Nil

Conflict of interest: None

period, after informed consent was sought, detailed history pertaining to demographic data and clinical parameters were recorded in semi-structured pro forma. Data were then tabulated in an MS Excel spreadsheet for statistical analysis.

If in any of these patients, surgical site infection was observed, pus culture and sensitivity were done.

Additionally, any systemic antibiotic use, need for secondary suturing, and the duration of postoperative hospital stay were also recorded. Furthermore, on POD 14 and 30, patients were followed up on a telephonic conversation to re-assess for presence of SSI and need for intervention.

\section{CDC Criteria for Defining a Surgical Site Infection (SSI) ${ }^{5}$}

- Superficial Incisional SSI: Infection occurs within 30 days after the operation and infection involve only skin or subcutaneous tissue of the incision.

(c) Jaypee Brothers Medical Publishers. 2021 Open Access This article is distributed under the terms of the Creative Commons Attribution 4.0 International License (https://creativecommons.org/licenses/by-nc/4.0/), which permits unrestricted use, distribution, and non-commercial reproduction in any medium, provided you give appropriate credit to the original author(s) and the source, provide a link to the Creative Commons license, and indicate if changes were made. The Creative Commons Public Domain Dedication waiver (http://creativecommons.org/publicdomain/zero/1.0/) applies to the data made available in this article, unless otherwise stated. 
- Deep Incisional SSI: Infection occurs within 30 days after the operation if no implant is left in place or within 1 year if implant is in place and the infection appears to be related to the operation and infection involves deep soft tissues (e.g., fascial and muscle layers) of the incision.

- Organ/Space SSI: The infection occurs within 30 days after the surgery if no implant is left in place or within 1 year if implant is in place. In this case, the infection appears to be related to the operation and the infection could involve any part of the anatomy (e.g., organs or spaces), other than the incision that was opened or manipulated during an operation.

Distribution of data for quantitative variables was assessed under normal distribution and summarized as mean and standard deviation. Categorical variables were summarized as proportions. Association of the potential risk factors with infection was assessed using chi-square test. The multivariate logistic regression was used to determine the significant prognostic factors responsible for infection adjusted for confounders. The analysis was done using SPSS v.19 statistical software. All the statistical analysis was carried out at $5 \%$ level of significance, and a $p$ value of $<0.05$ was considered statistically significant.

\section{Results}

In the 548 women included in the study, the mean age of the women was $26.20 \pm 4.385$ years and $76 \%$ of women were in between 20 and 29 years (Table 1). Half of the women were primigravidae $(51 \%)$. The mean BMI was $25.965 \pm 4.18 \mathrm{~kg} / \mathrm{m}^{2}$. More than half of the women $(55.8 \%)$ were either obese or overweight. Four-fifths of women (83.5\%) had term pregnancies, i.e., with 37 completed weeks at the time of surgery $(57.3 \%)$.

Incidence rate of SSI in our hospital was $7.3 \%$. Most of the infections were superficial SSI. Only three cases (7.5\%) were deep SSI. Two-thirds of infections were diagnosed by POD 5. Only one case was detected by the post-discharge surveillance. Escherichia coli was isolated from $42 \%$ of infected wounds. One-third of patients had a polymicrobial etiology. Gram-negative organisms showed high sensitivity to aminoglycoside group of antibiotics (Table 2).

\section{Antenatal Risk Factors}

SSI was developed in $14.6 \%$ of obese women. Four-fifths of women studied were anemic, and $5.8 \%$ of women were severely anemic, among which $25 \%$ of women developed SSI. There was no significant association between medical illnesses like hypertension, diabetes, heart diseases, and wound infections.

\section{Intrapartum Risk Factors}

SSI was developed in $11.5 \%$ of women who underwent induction. One-fourth of the cases with prolonged duration of ruptured membranes developed SSI when compared to $2.7 \%$ with intact membranes. One-third of cases who had more than 10 vaginal examinations developed infection (4.6\%).

Women who were operated in an emergency had a significantly higher risk of infection (9.5\%) when compared to elective surgeries (0.72\%).

All women received a single dose of one gram ceftriaxone as a prophylactic antibiotic after the test dose as per the hospital protocol. Fourteen percentage women had a prolonged course of prophylactic antibiotics, with no statistically significant difference in rate of infection from women that received a single dose.

One-third of women (30\%) with interrupted sutures developed infection when compared to $3.7 \%$ with subcuticular sutures. Similarly, $11.1 \%$ of women in whom silk was used for skin closure developed SSI when compared to 3\% with monocryl sutures.

Using multiple logistic regression model (Table 3), severe anemia, obesity, emergency procedure, prolonged duration of surgery of more than 90 minutes, and silk as suture material for skin closure significantly increased the likelihood of infection with adjusted odds ratio of 3.90 .

Table 1: Demographic data of the women and their effect on SSI

\begin{tabular}{|c|c|c|c|c|}
\hline Demographic characteristics & Total no (\% among the total) & Without SSI (\% proportion) & With SSI (\% proportion) & $p$ value \\
\hline \multicolumn{5}{|l|}{ 1. Age (years) } \\
\hline$<20$ & $13(2.38)$ & $12(92.3)$ & $1(7.7)$ & \multirow[t]{4}{*}{0.929} \\
\hline $20-29$ & $421(76.82)$ & $392(93.1)$ & $29(6.9)$ & \\
\hline $30-35$ & $98(17.89)$ & $89(90.8)$ & $9(9.2)$ & \\
\hline$>35$ & $16(2.91)$ & $15(93.8)$ & $1(6.3)$ & \\
\hline \multicolumn{5}{|l|}{ 2. BMI } \\
\hline Normal & $242(44.2)$ & $227(93.8)$ & $15(6.2)$ & \multirow[t]{3}{*}{0.020} \\
\hline Overweight & $224(40.8)$ & $211(94.2)$ & $13(5.8)$ & \\
\hline Obese & $82(15)$ & $70(85.4$ & $12(14.6)$ & \\
\hline \multicolumn{5}{|l|}{ 3. Parity } \\
\hline Primigravida & $281(51.3)$ & $257(91.5)$ & $24(8.5)$ & \multirow[t]{3}{*}{0.067} \\
\hline Multigravida with unscarred uterus & $25(4.5)$ & $21(84.0)$ & $4(16)$ & \\
\hline Multigravida with prev CS & $242(44.2)$ & $230(95.0)$ & $12(5)$ & \\
\hline \multicolumn{5}{|l|}{ 4. Gestational age (weeks) } \\
\hline$<37$ & $87(15.87)$ & $77(88.5)$ & $10(11.5)$ & \multirow[t]{3}{*}{0.224} \\
\hline $37-39^{+} 6$ & $314(57.3)$ & $295(93.9)$ & $19(6.1)$ & \\
\hline$\geq 40$ & $147(26.83)$ & $136(92.5)$ & $11(7.5)$ & \\
\hline
\end{tabular}


Table 2: Antibiotic sensitivity pattern among the common gram-negative organisms

\begin{tabular}{lcllll}
\hline Organism & $A k$ & $G$ & Ceftr & Cip & Cef \\
\hline Escherichia coli & $100 \%$ & $68.4 \%$ & $21.2 \%$ & $52.6 \%$ & $31.6 \%$ \\
Klebsiella & $76.2 \%$ & $55.6 \%$ & $22.2 \%$ & $22.2 \%$ & $44.4 \%$ \\
Pseudomonas sp. & $75 \%$ & $50 \%$ & $25 \%$ & $0 \%$ & $0 \%$ \\
Acinetobacter spp. & $40 \%$ & $20 \%$ & $0 \%$ & $0 \%$ & $0 \%$ \\
\hline
\end{tabular}

Ak, amikacin; Ceftr, ceftriaxone; Cip, ciprofloxacin; Cef, ceftazidime; $\mathrm{G}$, gentamicin

Table 3: Risk factors for SSI with adjusted odds ratio using multiple logistic regression model

\begin{tabular}{|c|c|c|c|}
\hline Risk factor & $\begin{array}{l}\text { No. of } \\
\text { cases (n) }\end{array}$ & $\begin{array}{l}\text { Adjusted OR } \\
(95 \% \mathrm{Cl})\end{array}$ & $p$ value \\
\hline \multicolumn{4}{|l|}{ 1. Anemia } \\
\hline $\begin{array}{l}\text { Normal Hb } \\
(>11 \mathrm{~g} / \mathrm{dL})\end{array}$ & 110 & - & 0.021 \\
\hline $\begin{array}{l}\text { Mild anemia } \\
(10-11 \mathrm{~g} / \mathrm{dL})\end{array}$ & 130 & $0.599(0.190-1.884)$ & \\
\hline $\begin{array}{l}\text { Moderate anemia } \\
(7-10 \mathrm{~g} / \mathrm{dL})\end{array}$ & 276 & $0.628(0.240-1.643)$ & \\
\hline $\begin{array}{l}\text { Severe anemia } \\
(<7 \mathrm{~g} / \mathrm{dL})\end{array}$ & 32 & $3.451(0.979-12.159)$ & \\
\hline \multicolumn{4}{|l|}{ 2. BMI category } \\
\hline Normal & 242 & - & 0.047 \\
\hline Overweight & 224 & $0.680(0.291-1.586)$ & \\
\hline Obese & 82 & $2.244(0.885-5.694)$ & \\
\hline \multicolumn{4}{|c|}{ 3. No. of PV category } \\
\hline$<5$ & 392 & - & 0.418 \\
\hline $5-10$ & 143 & $1.578(0.703-3.541)$ & \\
\hline 10-15 & 13 & $2.385(0.464-12.254)$ & \\
\hline \multicolumn{4}{|c|}{ 4. Rupture of membrane category } \\
\hline No ROM & 256 & - & 0.166 \\
\hline ROM $<6$ hours & 119 & $0.536(0.186-1.546)$ & \\
\hline ROM 6-12 hours & 89 & $0.877(0.291-2.641)$ & \\
\hline ROM 12-24 hours & 52 & $1.955(0.521-7.339)$ & \\
\hline ROM $>24$ hours & 32 & $0.377(0.128-1.110)$ & \\
\hline \multicolumn{4}{|c|}{ 5. Urgency of the surgery } \\
\hline Elective & 137 & - & 0.037 \\
\hline Emergency & 411 & $9.401(1.140-77.557)$ & \\
\hline \multicolumn{4}{|c|}{ 6. Duration of surgery category } \\
\hline$<60$ minutes & 315 & - & 0.036 \\
\hline 61-90 minutes & 187 & $2.293(1.057-4.972)$ & \\
\hline$>90$ minutes & 46 & $2.454(0.771-7.816)$ & \\
\hline \multicolumn{4}{|c|}{ 7. Suture for skin closure } \\
\hline Monocryl & 198 & - & 0.007 \\
\hline Prolene & 55 & $1.320(0.224-7.772)$ & \\
\hline Vicryl & 25 & $2.096(0.308-14.259)$ & \\
\hline Silk & 270 & $3.90(1.452-10.472)$ & \\
\hline
\end{tabular}

\section{Discussion}

Wound infections are reported to be the second most frequently reported health care-associated infection, even in obstetric practice. $^{7}$
The incidence of SSI in our study was $7.3 \%$ including the postdischarge surveillance for 30 days. In a study done by De et al., ${ }^{8}$ it was $24.2 \%$, much higher than our study. Studies done in other parts of India and the world showed varying rates, i.e., 6.03\% in Assam, India, $9,10,11$ and $5 \%$ in United States ${ }^{12}$ and New Zealand. ${ }^{13}$

In this study, BMI was found to be an independent risk factor for SSI. This is possibly due to relative avascularity of adipose tissue, greater tissue handling and trauma, and prolonged duration of surgery. SSI was developed in $58.6 \%$ of obese women (as against $48 \%$ of women with normal BMI). Similar results were found by Johnson et al. ${ }^{14}$

The mean duration of preoperative hospital stay was $3.76 \pm 6.38$ days, and there was statistically significant difference in this duration and rate of SSI. This was contrary to the findings in a study by De et al. ${ }^{8}$

Preoperative anemia negatively affects the immune status, thereby increasing risk of SSI. Women with severe anemia were found to have an increased risk of developing SSI ( 25 vs $7.2 \%$ in non-anemic women). The results were comparable to another study by Talukdar et al. ${ }^{11}$

Uncontrolled diabetes mellitus, including gestational diabetes mellitus, is an important predictor of wound infection..$^{15} \mathrm{~A}$ higher rate of infection was seen among the diabetic women (14 vs $5.15 \%$ ). Only $14 \%$ of women in our present study were diabetic. In a study conducted by Ansar et al., 7\% of women included in the study were diabetic. ${ }^{16}$

The rate of infection in the patients undergoing induction was significantly higher (11.4 vs $4.55 \%$ ). This could be explained by the prolonged duration of labor and multiple vaginal examinations. However, there are no studies done in the past to analyze the same.

Premature rupture of membrane (PROM) and the prolonged duration of labor are important risk factors for infection. The rate of infection was much higher in women with PROM of more than 24 hours (18.8 vs $2.7 \%$ in women with intact membrane). A study in Assam by Talukdar et al. showed that women with PROM had a higher risk of SSI than those without it (25.6 vs $16.2 \%) .{ }^{11} \mathrm{SSI}$ rate was higher in women that underwent multiple vaginal (30.8\%).

The timing of the first dressing change has a significant implication in the incidence of SSI postoperatively. In a study done by Metgud MC and team, dressing change on third day postoperatively had increased risk of infection. ${ }^{18}$

Advancing age is a parameter that might impair healing postoperatively, which we also observed postoperatively. In a study done by Abbey et al., the rate of SSI was significantly higher than the group of younger patients. ${ }^{19}$

Prolonged duration of surgery is an important negative risk factor for SSI. In this study, we found that duration of more than 90 minutes is significantly associated with increased risk of SSI. In another similar study conducted in Assam, $63.3 \%$ of patients with prolonged duration of surgery of more than 40 minutes were infected, when compared to $41 \%$ of patients with duration of less than 40 minutes. ${ }^{11}$

In the present study, skin was closed by interrupted mattress sutures in half of the cases (51\%). One-third of women with mattress sutures developed infection compared to $3.7 \%$ with subcuticular sutures. Johnson et al. reported a higher rate of infection when skin closed with either interrupted sutures or staples, significantly higher when compared to subcuticular sutures. ${ }^{14}$ Ghuman et al. 
compared skin closure by sutures and staples and did not find any difference with respect to rate of infection..$^{13}$ In a study by Islam and Ehsan, comparison was made between subcutaneous tissue closure if done and skin closure using vicryl. ${ }^{17}$

Common causative organisms of the postsurgical wound infections in the present study were gram-negative organisms, followed by Staphylococcus aureus. Talukdar et al. reported one-third of the infected cases (37.96\%) to be caused by S. aureus. ${ }^{11}$

\section{Conclusion}

Patient factors that affected infection rates were severe anemia and obesity. Antenatal factors such as prolonged rupture of membranes, multiple vaginal examinations, and induction of labor were associated with significant SSI. Surgery-related factors were emergency procedures, prolonged duration of surgery, and silk as a suture material for skin closure with mattress suture.

\section{Limitations}

Telephonic post-discharge surveillance is not an accurate method to determine the actual incidence of infection. It is limited by patient's ability to diagnose the infection and report it. This would have led to underestimation of actual incidence of SSI.

\section{Compliance with Ethical Standards Ethical Approval}

The ethical approval was obtained from Institutional Ethics Committee.

\section{Informed Consent}

Informed consent was obtained from all individual participants included in the study.

\section{OrCID}

Esha R Shanbhag @ https://orcid.org/0000-0002-5768-9326 Veena $P$ ○ https://orcid.org/0000-0002-0832-8321

\section{References}

1. Hillan EM. Post-operative morbidity following cesarean delivery. J Adv Nurs 1995;22(6):1035-1042. DOI: 10.1111/j.1365-2648.1995. tb03102.x.

2. Ezechi OC, Fasubaa OB, Dare FO. Socioeconomic barrier to safe motherhood among booked patients in rural Nigerian communities. J Obstet Gynaecol 2000;20(1):32-34. DOI: 10.1080/01443610063426.

3. Ward VP, Charlett A, Fagan J, et al. Enhanced surgical site infection surveillance following cesareansection: experience of a multicentre collaborative post-discharge system. J Hosp Infect 2008;70(2): 166-173. DOI: 10.1016/j.jhin.2008.06.002.
4. Moir-Bussy BR, Hutton RM, Thompson JR. Wound infection after cesarean section. J Hosp Infect 1984;5(4):359-370. DOI: 10.1016/01956701(84)90003-3.

5. Horan TC, Gaynes RP, Martone WJ, et al. CDC definitions of nosocomial surgical site infections 1992: a modification of surgical wound infections. Infect Control Hosp Epidemiol 1992;13(10):606-608. Doi: 10.1016/s0196-6553(05)80201-9

6. Kinsella SM, Scrutton MJL. Assessment of a modified four-category classification of urgency of cesarean section. J Obstet Gynaecol 2009;29(2):110-113. DOI: 10.1080/01443610802585546.

7. Emori TG, Gaynes RR. An overview of nosocomial infections, including the role of the microbiology lab. Clin Microbiol Rev 1993;6(4):428-444. DOI: 10.1128/CMR.6.4.428.

8. De D, Saxena S, Mehta G, et al. Risk factor analysis and microbial etiology of surgical site infections following lower segment cesarean section. Int J Antibiot 2013;2013:1-6. DOI: 10.1155/2013/ 283025.

9. Shrestha S, Shrestha R, Shrestha B, et al. Incidence and risk factors of surgical site infection following cesarean section at Dhulikhel Hospital. Kathmandu Univ Med J 2014;46(2):113-116. DOI: 10.3126/ kumj.v12i2.13656.

10. Amenu D, Belachew T, Araya F. Surgical site infection rate and risk factors among obstetric cases of Jimma University specialized hospital, southwest Ethiopia. Ethiop J Health Sci 2011;21(2):91-100. DOI: 10.4314/ejhs.v21i2.69049.

11. Talukdar RK, Gharphalia DJ, Acharjee U. Surgical site infection following emergency LSCS - to find out the incidence, risk factors and commonly associated bacteria. Sch J Appl Med Sci 2015;3(8A):2794-2801.

12. Olsen MA, Butler AM, Willers DM, et al. Risk factors for surgical site infection after low transverse cesarean section. Infect Control Hosp Epidemiol 2008;29(6):477-484. DOI: 10.1086/587810.

13. Ghuman $M$, Rohlandt $D$, Joshy $G$, et al. Post cesarean section surgical site infection: rate and risk factors. N Z Med J 2011; 124(1339):32-36.

14. Johnson A, Young D, Reilly J. Cesarean section surgical site infection surveillance. J Hosp Infect 2006;64(1):30-35. DOI: 10.1016/ j.jhin.2006.03.020.

15. Tran TS, Jamulitrat S, Chongsuvivatwong V, et al. Risk factors for postcesarean surgical site infection. Obstet Gynecol 2000;95(3): 367-371. DOI: 10.1016/s0029-7844(99)00540-2.

16. Ansar A. Surgical site infection in obstetrics practice. Pak J Surg 2013;18(2):68-73.

17. Islam A, Ehsan A. Comparison of suture material and technique of closure of subcutaneous fat and skin in cesarean section. $N$ Am J Med Sci 2011;3(2):85-88. DOI: 10.4297/najms.2011.385.

18. Metgud MC, Kataria A, Nadipally SR, et al. Incidence of wound dehiscence following obstetric and gynecological surgeries at a Tertiary Care Hospital: a retrospective study. JSouth Asian Feder Obstet Gynaecol 2020;12(2):73-78. DOI: 10.5005/jp-journals-10006-1763.

19. Abbey $R$, Mohan M, Malik N, et al. Surgical site infections in a rural teaching hospital of North India. Int J Adv Integ Med Sci 2017;2(1): 11-16. DOI: 10.5005/jp-journals-10050-10066. 